\title{
Konno-rastan procedure combined with manougian root en- largement for small aortic root
}

\author{
Metin Onur Beyaz ${ }^{\mathrm{a},{ }^{*}}$, Nur Gizem Elipek ${ }^{\mathrm{b}}$, Ibrahim Demir ${ }^{\mathrm{c}}$, Didem Melis Oztas ${ }^{\mathrm{d}}$, Mustafa Ozer \\ Ulukan $^{a}$, Turkay Saritas ${ }^{\mathrm{e}}$, Murat Ugurlucan ${ }^{\mathrm{a}}$, Halil Turkoglu ${ }^{\mathrm{a}}$
}

${ }^{a}$ Department of Cardiovascular Surgery, Faculty of Medicine, Istanbul Medipol University, Istanbul, Turkey.
${ }^{b}$ Faculty of Medicine, Istanbul Medipol University, Istanbul, Turkey.
${ }^{c}$ Department of Cardiovascular Surgery, Istanbul Medical Faculty, Istanbul University, Istanbul, Turkey.
${ }^{d}$ Cardiovascular Surgery Clinic, Bagcilar Education and Research Hospital, Istanbul, Turkey.
${ }^{e}$ Department of Pediatric Cardiology, Faculty of Medicine, Istanbul Medipol University, Istanbul, Turkey.

Abstract

Aortic stenosis is a rarely seen condition in the pediatric population. Valve replacement is a treatment option for patients who do not benefit from medical or interventional procedures. In this report, we described our surgical treatment strategy in a 17-year-old patient who developed patient-prosthesis mismatch long after initial aortic valve replacement during the childhood period.

Keywords: Konno-rastan procedure; manouguian technique; aortic root enlargement

\section{INTRODUCTION}

Aortic stenosis is a rarely seen condition in the pediatric population. The known incidence is 3.8/10.000 in live births ${ }^{[1]}$. Balloon angioplasty is the most common treatment method in the neonatal period for aortic stenosis ${ }^{[2]}$. Valve replacement is another treatment option for patients who do not benefit from medical and interventional procedures ${ }^{[3]}$. Valve replacement options include Ross technique, Konno technique, and biological or mechanical valve replacement. As the patients grow, patient prosthesis mismatch still appears as an important factor who underwent valve replacement surgery ${ }^{[4]}$. In this report, we described the surgical treatment of a 17-year-old patient who developed patient-prosthesis mismatch due to aortic valve replacement history.

\footnotetext{
* Corresponding author: Metin Onur Beyaz

Mailing address: Department of Cardiovascular Surgery, Faculty of Medicine, Istanbul Medipol University, Medipol Mega University Hospital, TEM Avrupa Otoyolu Goztepe Cikisi, No:1, 34214 Bagcilar, Istanbul, Turkey.

E-mail: metinonurbeyaz@gmail.com

Received: 11 October 2020 / Accepted: 30 November 2020
}

\section{CASE REPORT}

A 17-year-old male patient was admitted to our clinic with complaints of increased chest pain and shortness of breath after exercise who underwent aortic valve replacement surgery with a No: 17 mechanical aortic valve with Manouguian aortic root enlargement technique due to diagnosis of aortic stenosis 10 years ago.

There was no family history. All biochemical markers found normal. The cardiothoracic index was increased in his chest $x$-ray. The patient was overweight with a body mass index of $27.19 \mathrm{~kg} / \mathrm{m}^{2}$. Echocardiography showed intact mechanical valve prosthesis with low effective orifice area (Indexed EoA: 0.70) and ventricular hypertrophy. The ejection fraction was measured at $55 \%$. A mean transaortic pressure gradient was measured $24 \mathrm{mmHg}$ with a maximal aortic velocity of $3.4 \mathrm{~m} / \mathrm{s}$. Additionally, there was mild pulmonary insufficiency and stenosis, and mild mitral insufficiency. Aortic valve replacement surgery was planned after the patient and his family was informed about the operation and the necessary operation consent was obtained. 


\section{SURGICAL TECHNIQUE}

Sternotomy incision was made along the old sternotomy incision line. Adhesions were removed. The pericardium was opened and suspended. Aortic cannulation and bicaval venous cannulations were performed following systemic heparinization. Cardiopulmonary bypass was initiated and the patient was cooled down to $28 \mathrm{C}$. A vent catheter was inserted into the left atrium from the right superior pulmonary vein. Cardiac arrest and myocardial protection were provided with direct cold blood cardioplegia after aortic clamp and aortotomy. The old aortic valve was excised. The pericardium used for the old Manougian procedure was found to be calcified and resected. The right ventricle outflow tract (RVOT) was opened and an incision was extended to the interventricular septum. The septum and the anterior aortic root was enlarged with a dacron patch (Konno-Rastan procedure). The Manougian type posterior enlargement was made with a dacron patch (Figure 1). No: 27 mechanical valve was implanted to the aortic root with the help of Teflon reinforced 2/0 ti-cron sutures (Figure 2). The aortotomy was closed using a dacron patch. Pulmonary comissurotomy was

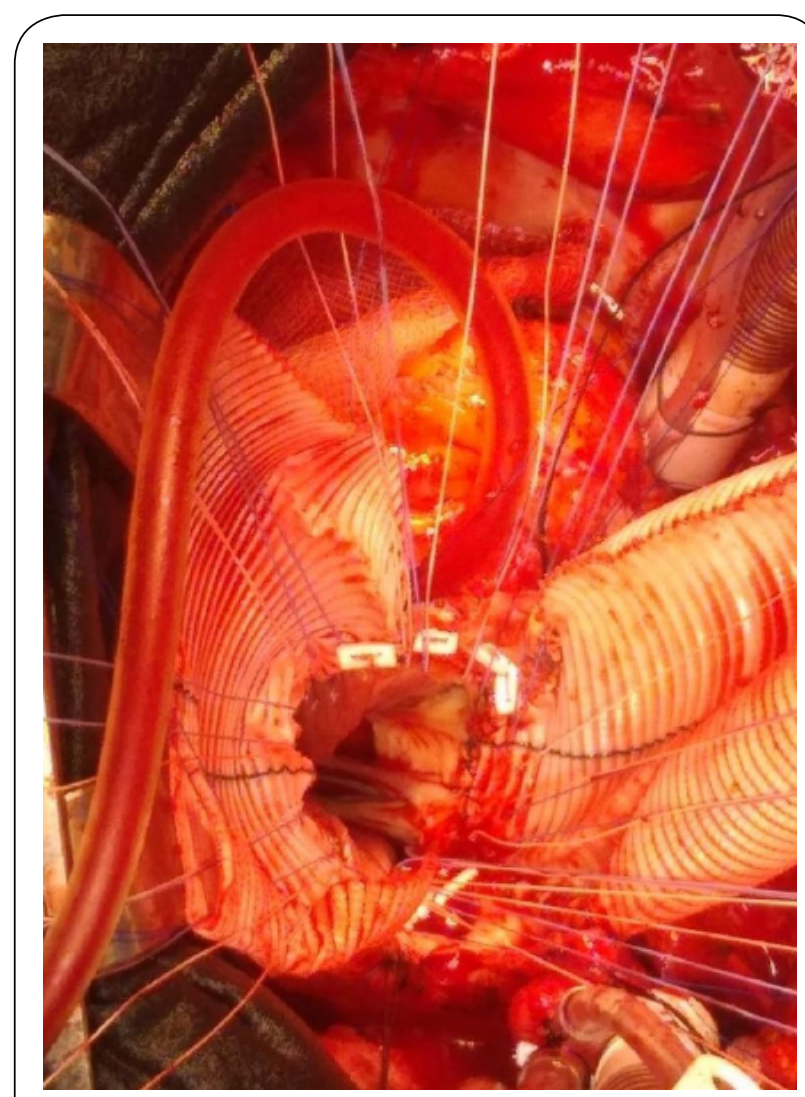

Figure 1: The Manouguian posterior expansion and KonnoRastan anterior expansion were performed using Dacron patches.

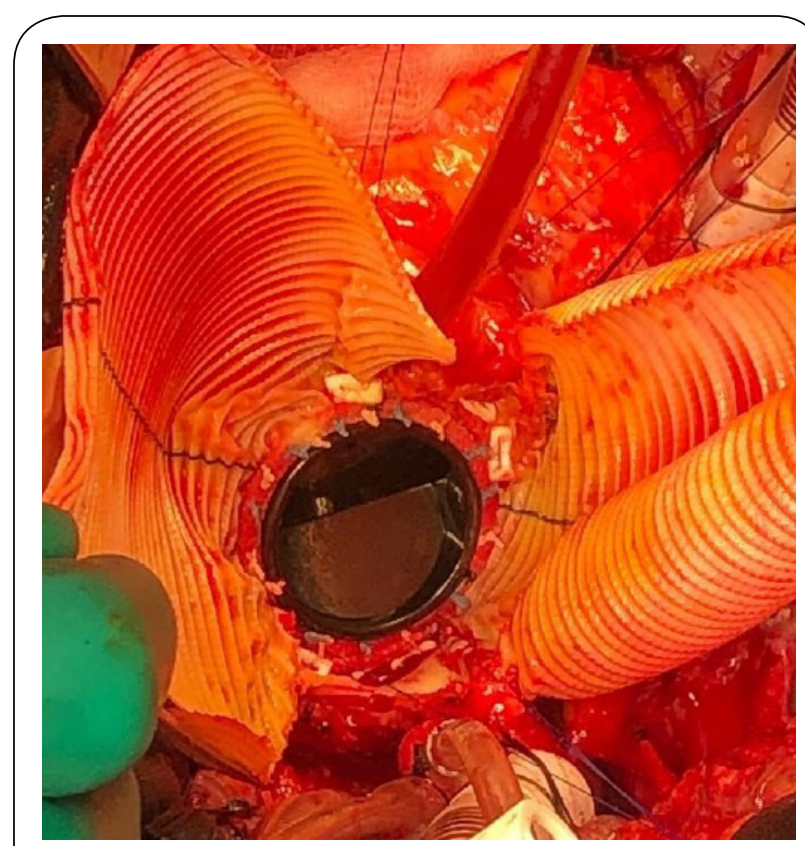

Figure 2: No: 27 St. Jude mechanical valve was placed with the help of Teflon reinforced 2/0 ti-cron sutures.

performed to relieve mild pulmonary stenosis. RVOT was reconstructed using a dacron patch (Figure 3). Weaning of the cardiopulmonary bypass was achieved with milrinone $(0.75 \mathrm{mcg} / \mathrm{kg} / \mathrm{min})$ and adrenalin $(0.05$ $\mathrm{mcg} / \mathrm{kg} / \mathrm{min}$ ) infusion. The operation was ended conventionally. The patient was taken to the intensive care unit. The cardiopulmonary bypass and cross-clamp times were 138 minutes and 106 minutes, respectively. The patient was extubated in the 6 th hour. The intensive care unit stay was 56 hours. Postoperative course was uneventful and the patient was discharged from the hospital after 8 days.

Postoperative echocardiography indicated no significant transaortic gradient (max: 4-5 mmHg) with normal myocardial functions. She has been followed active, well, and asymptomatic for more than 18 months.

\section{DISCUSSION}

Causes of aortic stenosis vary from congenital bicuspid aortic valve, calcification to rheumatic fever ${ }^{[5]}$. Untreated aortic stenosis has a classical triad composed of dyspnea, syncope and angina. Heart failure and rhythm disorders may be added to these symptoms in later stages ${ }^{[6]}$. PPM should always be avoided as it has been associated with perioperative mortality, reduced longterm survival, consistent symptoms, and slow regression of LV mass. Meta-analysis has reported that severe PPM is associated with reduced long-term survival ${ }^{[7]}$. Patient-prosthesis incompatibility is one of the prob- 


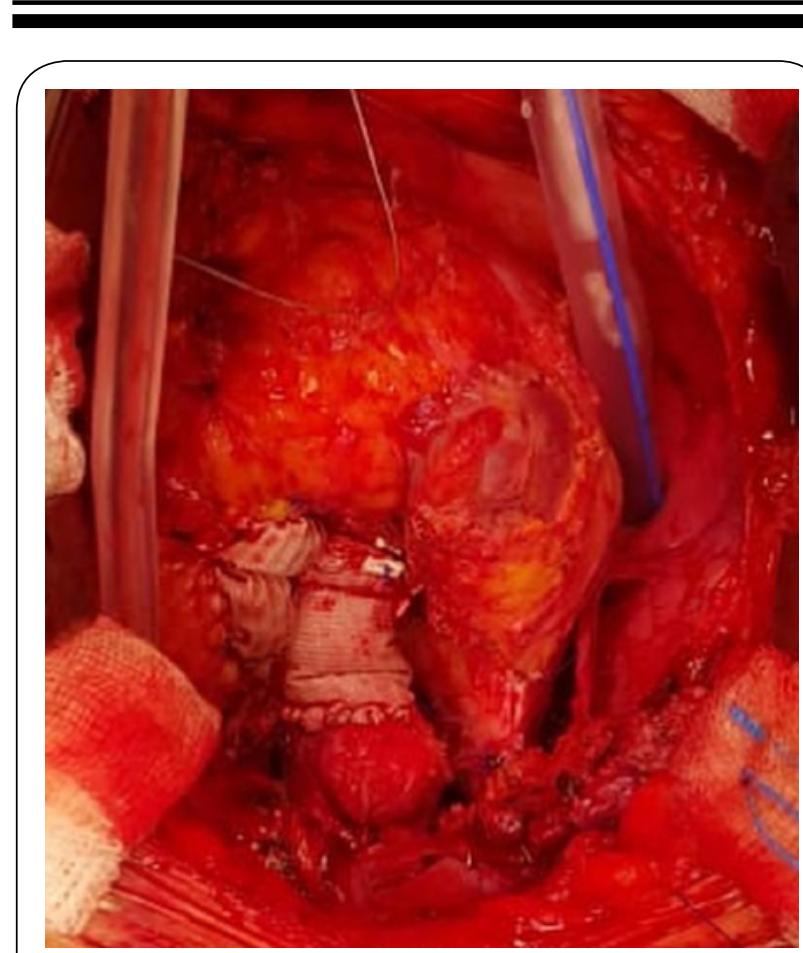

Figure 3: Ascending aorta and the right ventricular outflow tract are reconstructed with dacron patches.

lems affecting the quality of life of patients after aortic valve replacement surgery and this situation may be more prominent especially in children as their growth continue ${ }^{[8]}$. It has been shown that aortic root enlargement operations can be performed to overcome PPM, and the incidence of PPM is reduced with root enlargement operations. Konno-Rastan and Manouguian procedures are the two most commonly preferred root augmentation operations for patients. When KonnoRastan and Manouguian type aortic enlargement were together performed, it is possible to implant larger aortic valves to the aortic root especially in the growing population ${ }^{[9]}$. The Ross procedure is another option and by its nature, the patient's pulmonary autograft is used to replace the aortic valve ${ }^{[10]}$. Ross procedure could have been an alternative; however, our patient was not found suitable for Ross procedure ten years ago due to having a bicuspid pulmonary valve showing mild pulmonary insufficiency and minimally fibrotic leaflets. A No: 17 mechanical valve could be implanted following posterior aortic root enlargement at that age. As the child grew up in time, this mechanical valve remained small as expected. What needs to be done in the meantime was to replace the valve.

\section{CONCLUSION}

A cardiac surgeon should be well skilled with the root enlargement procedures which may be helpful at the time of aortic valve replacement for young obese men and women with small aortic roots. Combined aortic root enlargement techniques could be considered in the presence of bodily growth potential.

\section{DECLARATIONS}

\section{Authors' contributions}

Made substantial contributions to conception and design of the study and performed data analysis and interpretation: Beyaz MO, Elipek NG, Demir I, Oztas DM, Ulukan MO, Ugurlucan M, Turkoglu H.

Performed data acquisition, as well as provided administrative, technical, and material support: Ugurlucan $\mathrm{M}$, Turkoglu H, Ulukan MO.

\section{Availability of data and materials}

All data of the patients are stored at Medipol University where the operations are performed.

\section{Conflict of interest}

All authors declared that there are no conflicts of interest.

\section{Ethical approval}

We studied in accordance with the ethical guidelines set by the Helsinki Declaration and the International Association of Heart and Lung Transplantation (ISHLT). A case report was prepared after obtaining a signed document and approval from the patient and his family for procedures.

\section{REFERENCES}

1. Olofsson, C. K., Hanseus, K., Ramgren, J. J., Synnergren, M. J., \& Sunnegårdh, J. (2020). A national study of the outcome after treatment of critical aortic stenosis in the neonate. Cardiology in the Young, 30(9), 1321-1327.

2. Nişli, K., Serra Karaca, D., \& Dindar, A. (2016). Yenidoğanda umblikal ven yoluyla aort balon valvüloplastisi: Ülkemizdeki ilk tecrübe. Turk Kardiyol Dern Ars, 44(6), 521-523.

3. San Román, J. A., Vilacosta, I., Antunes, M. J., Iung, B., Lopez, J., \& Schäfers, H. J. (2020). The 'wait for symptoms' strategy in asymptomatic severe aortic stenosis. Heart, 106(23), 1792-1797.

4. Kim, H. J., Kim, H. J., Kim, J. B., Jung, S. H., Choo, S. J., Chung, C. H., \& Lee, J. W. (2020). Prosthesis-patient mismatch after surgical aortic valve replacement in patients with aortic stenosis. Interactive CardioVascular and Thoracic Surgery, 31(2), 152-157.

5. Maganti, K., Rigolin, V.H, Sarano, M.E, Bonow, R.O. (2009). Valvular heart disease: diagnosis and management. Mayo 
Clin Proc, 85(5):483-500.

6. Minners, J., Rossebo, A., Chambers, J. B., Gohlke-Baerwolf, C., Neumann, F. J., Wachtell, K., \& Jander, N. (2020). Sudden cardiac death in asymptomatic patients with aortic stenosis. Heart, 106(21), 1646-1650.

7. Head, S. J., Mokhles, M. M., Osnabrugge, R. L., Pibarot, P., Mack, M. J., Takkenberg, J. J., ... \& Kappetein, A. P. (2012). The impact of prosthesis-patient mismatch on longterm survival after aortic valve replacement: a systematic review and meta-analysis of 34 observational studies comprising 27186 patients with 133141 patient-years. European heart journal, 33(12), 1518-1529.

8. Nardi, P., Russo, M., Saitto, G., \& Ruvolo, G. (2018). The prognostic significance of patient-prosthesis mismatch after aortic valve replacement. The Korean Journal of Thoracic and Cardiovascular Surgery, 51(3), 161.

9. Khan, F. W., \& Said, S. M. (2019). Konno-rastan combined with manougiaun root enlargement for small aortic root with coronary anomaly in a young woman. Heart Views: The Official Journal of the Gulf Heart Association, 20(4), 172.

10. Erek, E., Kenan Yalcinbas, Y., Sarioglu, A., \& Sarioglu, T. (2004). Double root re-replacement after Ross-Konno operation in a patient with straight back syndrome: clamshell approach. Interactive cardiovascular and thoracic surgery, 3(4), 575-577. 